\title{
Continuous propofol and bolus propofol result in similar sedative use during endoscopic retrograde cholangiopancreatography: A retrospective study
}

\author{
Derya Seyitoglu, Erol Iskender, Ahmied Azzarok and Abdurrahman Sagir* \\ Department of Gastroenterology, Academic Teaching Hospital Bethesda Duisburg, 47053 Duisburg, Germany
}

\begin{abstract}
Background: Endoscopic retrograde cholangiopancreatography is a complex, lengthy, and uncomfortable procedure. Therefore, deep sedation is required for its successful completion. Generally, a combination of midazolam and propofol is used, with propofol being administered as a continuous infusion or an intermittent bolus.

Aim: In this retrospective study, we compared propofol use in patients receiving a continuous infusion with those receiving an intermittent bolus.

Methods: Of the 121 included patients, 87 received an intermittent bolus application (bolus group) and 34 received a continuous infusion (perfusor group) of propofol. An initial dose of $2.5 \mathrm{mg}$ midazolam was applied to all patients to induce deep sedation, in addition to an initial dose of propofol that depended on body weight, blood pressure, and oxygen saturation. Procedure duration and total propofol dose were determined. Weight-adapted propofol dosage per minute of procedure was calculated.

Results: Total propofol dose was significantly correlated with procedure duration $(\mathrm{r}=0.685 ; \mathrm{p}<0.001)$. Total propofol dose was significantly higher in the perfusor group than in the bolus group $(352.1 \pm 27.8 \mathrm{mg}$ vs. $264.3 \pm 162.9 \mathrm{mg}$, respectively; $\mathrm{p}=0.015)$. Procedure duration was significantly longer in the perfusor group than in the bolus group $(48.3 \pm 27.8 \mathrm{~min}$ vs. $36.7 \pm 21.9 \mathrm{~min}$, respectively; $\mathrm{p}=0.038)$. Propofol dosage $(8.2 \pm 2.9 \mathrm{mg} / \mathrm{min} \mathrm{vs}$. $8.3 \pm 5.9 \mathrm{mg} / \mathrm{min}$; $\mathrm{p}=0.89)$ and weight-adjusted propofol dosage $(0.119 \pm 0.054 \mathrm{mg} / \mathrm{min} / \mathrm{kg}$ vs. $0.103 \pm 0.055 \mathrm{mg} / \mathrm{min} / \mathrm{kg} ; \mathrm{p}=0.31)$ were not significantly different between the two groups.
\end{abstract}

Conclusion: Both sedation regimens resulted in nearly identical propofol dosage, even when adjusted for body weight. There was no propofol dose reduction when propofol was administered as an infusion.

\section{Introduction}

Endoscopic retrograde cholangiopancreatography (ERCP) is an important procedure to diagnose and treat biliary and pancreatic diseases. Both the diagnosis and the intervention can be performed during a single session. However, the procedure is complex and uncomfortable. Therefore, adequate sedation is needed $[1,2]$. The purposes of sedation and analgesia are to relieve patient anxiety and discomfort, to improve the outcome of the procedure, and to diminish the patient's memory of the event $[3,4]$.

Midazolam has potent amnestic properties, some anxiolytic effects, and a short elimination half-life. A disadvantage of midazolam is its short elimination half-life. In fact, generally, it is not recommended that benzodiazepines be used alone for sedation during complex and/or long endoscopic procedures. Therefore, a combination of benzodiazepines and propofol is chosen frequently [5-7]. Propofol is a short-acting, intravenously administrated hypnotic agent that is often used in endoscopic sedation. Propofol has no specific antidote and a relative narrow therapeutic range. Propofol can cause deep sedation or abrupt respiratory failure. Despite these disadvantages, propofol has been proven safe for sedation during endoscopic procedures [8]. Nonetheless, endoscopy technicians must receive training prior to being authorized to administer propofol to patients [9].

Midazolam and propofol have been shown to act synergistically, and the dose of propofol can be reduced when used in combination with midazolam [10]. Propofol can be administered as a continuous infusion or an intermittent bolus. Both methods are well established and safe.

This retrospective study was conducted to compare propofol use in patients receiving a continuous infusion (perfusor group) with those receiving an intermittent bolus (bolus group) of propofol for sedation during ERCP. Patients receiving a continuous infusion have constant propofol levels. Therefore, we hypothesized that patients in the perfusor group would need less propofol during the procedure than patients in the bolus group.

\section{Material and methods}

\section{Patients and study design}

Patients who underwent therapeutic ERCP between January 2014 and July 2015 at the Academic Teaching Hospital were included in

Correspondence to: Abdurrahman Sagir, Department of Gastroenterology, Academic Teaching Hospital Bethesda Duisburg, 47053 Duisburg, Germany, Tel: +49 2036008 1300; Fax: + 492036008 1309; E-mail: sagirabdu@hotmail.com

Key words: ERCP, sedation, propofol, dosage

Received: September 02, 2017; Accepted: September 22, 2017; Published: September 25, 2017 

study

this retrospective study. The study protocol was approved by the ethics committee of the University of Düsseldorf.

Therapeutic ERCP procedures were performed by three experienced endoscopists. Trained nurses, with experience in therapeutic ERCP procedures, administered all medications and monitored patients. The endoscopist was assisted by one gastroenterology fellow or gastroenterologist and two nurses.

The level of sedation was defined according to the American Society of Anesthesiologists (ASA) classification: minimal, moderate, deep sedation, and general anesthesia. During therapeutic ERCP, deep sedation was the target level. Patient monitoring included non-invasive blood pressure measurements every $2 \mathrm{~min}$, pulse oximetry $\left(\mathrm{SpO}_{2}\right)$, and electrocardiography. Nasal oxygen was supplied at $41 / \mathrm{min}$.

All patients underwent sedation with midazolam in combination with propofol. The initial intravenous bolus dose of midazolam was $2.5 \mathrm{mg}$. The initial loading dose of propofol depended on body weight, blood pressure, and oxygen saturation. Next, propofol boli were injected following instruction from the endoscopist $(20-40 \mathrm{mg})$. In the perfusor group, the base rate varied between 30 and $50 \mathrm{ml} / \mathrm{h}$ regardless of the body weight; a Perfusor compact system (B. Braun Melsungen, Germany) was used.

\section{Statistical analysis}

Data were entered in SPSS (version 21.0, Inc., Munich, Germany). Patient data were anonymised and deidentified prior to analysis. A $\chi^{2}$ or Fisher's exact test (F-test) was used for the comparison of categorical variables, and a Mann-Whitney test was used for the comparison of continuous variables. The significance level was set to 0.05 , and all p-values were two-tailed. A Pearson's test was performed to study the correlation between total propofol dose and procedure duration.

\section{Results}

\section{Patient characteristics}

This retrospective study included a total of 121 patients. Their baseline characteristics are shown in Table 1.

Of the 121 patients, 87 received propofol as an intermittent bolus (bolus group) and 34 received propofol as a continuous infusion (perfusor group). The patient characteristics and the type of endoscopic intervention did not differ between the two groups (Table 2). A total of 180 endoscopic interventions (59 endoscopic papillotomies, 45 stone removals, 51 common bile duct stenting procedures, and 30 stent change procedures) were performed.

\section{Procedure characteristics according to method of propofol administration}

A total of 50 interventions were performed in the perfusor group (1.47 interventions per patient) compared with 135 interventions in the bolus group ( 1.55 interventions per patient). There was no significant difference in the number of interventions per patient between the two groups. However, the mean duration of the ERCP procedure was significantly longer in the perfusor group than in the bolus group $(48.3 \pm 27.8$ min vs. $36.7 \pm 21.9$, respectively; $\mathrm{p}=0.038$; Table 3$)$. The patients in the perfusor group received significantly more propofol compared to the patients in the bolus group $(352.1 \pm 27.8 \mathrm{mg}$ vs. 264.3 $\pm 162.9 \mathrm{mg}$, respectively; $\mathrm{p}=0.015$ ). The mean propofol base rate in the perfusor group was $33.4 \mathrm{ml} / \mathrm{h}$. Patients in the perfusor group received significantly less additional propofol boli compared to patients in the
Table 1. Baseline patient characteristics. Data are expressed as $\mathrm{n}(\%)$ or the mean $\pm \mathrm{SD}$. BMI: body mass index; AST: glutamic oxaloacetic transaminase; ALT: glutamate-pyruvate transaminase; GGT: gamma-glutamyl transferase; AP: alkaline phosphatase; CRP: C-reactive protein.

\begin{tabular}{|c|c|}
\hline Characteristic & \\
\hline Male $\mathrm{n}(\%)$ & $63(52)$ \\
\hline Age (years) & $67.9 \pm 15.2$ \\
\hline Weight $(\mathrm{kg})$ & $75.6 \pm 18.2$ \\
\hline Height $(\mathrm{m})$ & $1.68 \pm 0.09$ \\
\hline BMI $\left(\mathrm{kg} / \mathrm{m}^{2}\right)$ & $26.22 \pm 5.92$ \\
\hline Bilirubin $(\mathrm{mg} / \mathrm{dl})$ & $3.3 \pm 5.6$ \\
\hline GOT $(\mathrm{IU} / \mathrm{ml})$ & $86 \pm 112.5$ \\
\hline GPT $(\mathrm{IU} / \mathrm{ml})$ & $100.1 \pm 129.2$ \\
\hline GGT $(\mathrm{IU} / \mathrm{ml})$ & $462.2 \pm 545.2$ \\
\hline AP $(\mathrm{IU} / \mathrm{ml})$ & $292.6 \pm 319.9$ \\
\hline Leucocytes $/ \mathrm{nl}$ & $9 \pm 4.9$ \\
\hline CRP $(\mathrm{mg} / \mathrm{dl})$ & $5.1 \pm 7.1$ \\
\hline
\end{tabular}

Table 2. Patient characteristics according to method of propofol administration. Data are expressed as $\mathrm{n}(\%)$ or the mean \pm SD. BMI: body mass index; AST: glutamic oxaloacetic transaminase; ALT: glutamate-pyruvate transaminase; GGT: gamma-glutamyl transferase; AP: alkaline phosphatase; CRP: C-reactive protein.

\begin{tabular}{|c|c|c|c|}
\hline & $\begin{array}{c}\text { Perfusor group } \\
(\mathbf{n}=\mathbf{3 4})\end{array}$ & Bolus group (n=87) & P \\
\hline Male, $\mathrm{n}(\%)$ & $20(58)$ & $43(49)$ & 0.15 \\
\hline Age (years) & $64.3 \pm 17.3$ & $69.3 \pm 14.0$ & 0.103 \\
\hline Weight $(\mathrm{kg})$ & $73.2 \pm 17.7$ & $76.5 \pm 18.3$ & 0.37 \\
\hline Height (m) & $1.69 \pm 0.08$ & $1.68 \pm 0.09$ & 0.46 \\
\hline BMI (kg/m $)$ & $24.9 \pm 4.9$ & $26.7 \pm 6.1$ & 0.13 \\
\hline GOT (IU/ml) & $69.9 \pm 67.7$ & $92.3 \pm 125.2$ & 0.33 \\
\hline GPT (IU/ml) & $87.9 \pm 118.8$ & $104.9 \pm 132$ & 0.52 \\
\hline GGT (IU/ml) & $419.2 \pm 534.8$ & $479.1 \pm 548.3$ & 0.59 \\
\hline Bilirubin (mg/dl) & $2.54 \pm 5.35$ & $3.55 \pm 5.74$ & 0.38 \\
\hline AP (IU/ml) & $244.4 \pm 209.7$ & $311.5 \pm 351.9$ & 0.30 \\
\hline Leucocytes/nl & $9.5 \pm 4.2$ & $8.8 \pm 5.2$ & 0.47 \\
\hline CRP (mg/dl) & $5.31 \pm 6.5$ & $5.1 \pm 7.3$ & 0.83 \\
\hline $\begin{array}{c}\text { Intervention } \\
\text { Endoscopic } \\
\text { papillotomy, } \mathrm{n}(\%)\end{array}$ & $15(44.2)$ & $44(50.6)$ & 0.52 \\
\hline $\begin{array}{c}\text { Removal of stones, } \\
\mathrm{n}(\%)\end{array}$ & $9(26.5)$ & $36(41.4)$ & 0.127 \\
\hline $\begin{array}{c}\text { Stenting of the } \\
\text { common bile duct, } \\
\mathrm{n}(\%)\end{array}$ & $15(44.2)$ & $36(41.4)$ & 0.784 \\
\hline Stent-change, $\mathrm{n}(\%)$ & $11(32.4)$ & $19(21.8)$ & 0.229 \\
\hline
\end{tabular}

Table 3. Procedure characteristics according to method of propofol administration. Data are expressed as the mean \pm SD. ERCP: Endoscopic Retrograde Cholangiopancreatography; n.d., no data.

\begin{tabular}{|c|c|c|c|}
\hline & $\begin{array}{c}\text { Perfusor group } \\
\quad(n=34)\end{array}$ & $\begin{array}{c}\text { Bolus group } \\
\quad(n=87)\end{array}$ & $\mathbf{P}$ \\
\hline $\begin{array}{ll}\begin{array}{l}\text { Duration } \\
\text { procedure (min) }\end{array} & \text { of }\end{array}$ & $48.3 \pm 27.8$ & $36.7 \pm 21.9$ & 0.038 \\
\hline \multicolumn{4}{|l|}{ Total dose for ERCP } \\
\hline $\begin{array}{l}\text { Propofol (mg) } \\
\text { Midazolam (mg) }\end{array}$ & $\begin{array}{l}352.1 \pm 27.8 \\
2.54+0.6\end{array}$ & $\begin{array}{c}264.3 \pm 162.9 \\
2.54+0.3\end{array}$ & $\begin{array}{c}0.015 \\
0.78\end{array}$ \\
\hline $\begin{array}{l}\text { Propofol } \\
\text { rate }(\mathrm{ml} / \mathrm{h})\end{array}$ & $33.4 \pm 13.9$ & & \\
\hline Propofol boli & $3.9 \pm 2.8$ & $8.8 \pm 6.0$ & $<0.001$ \\
\hline $\begin{array}{l}\text { Propofol dose (mg)/ } \\
\text { min }\end{array}$ & $8.2 \pm 2.9$ & $8.3 \pm 5.9$ & 0.89 \\
\hline $\begin{array}{l}\text { Propofol dose }(\mathrm{mg}) / \\
\mathrm{min} / \mathrm{kg}\end{array}$ & $0.119 \pm 0.054$ & $0.103 \pm 0.055$ & 0.31 \\
\hline
\end{tabular}



study

bolus group $(3.9 \pm 2.8$ boli vs. $8.8 \pm 6.0$ boli, respectively; $\mathrm{p}<0.001)$ but the midazolam dose did not differ between the two groups $(2.54 \pm 0.6$ $\mathrm{mg}$ vs. $2.54 \pm 0.3 \mathrm{mg}$, respectively; $\mathrm{p}=0.78$ ).

Total propofol dose was significantly correlated with the duration of the procedure $(\mathrm{r}=0.695 ; \mathrm{p}<0.001$; Figure 1$)$. Next, we calculated the propofol dosage per minute by dividing the total propofol dose by the duration of the procedure. The propofol dosage per minute of procedure was similar in the perfusor and the bolus groups $(8.2 \pm 2.9$ $\mathrm{mg}$ propofol/min vs. $8.3 \pm 5.9 \mathrm{mg} \mathrm{propofol} / \mathrm{min}$, respectively; $\mathrm{p}=0.89$ ), even when adjusted for body weight $(0.119 \pm 0.0054 \mathrm{mg}$ propofol $/ \mathrm{min} /$ $\mathrm{kg}$ vs. $0.103 \pm 0.055 \mathrm{mg}$ propofol $/ \mathrm{min} / \mathrm{kg}$, respectively; $\mathrm{p}=0.31$ ).

\section{Discussion}

Due to its rapid recovery profile, the use of propofol has increased for many endoscopic procedures over the last decade [10-14]. Propofol produces safe, effective, and well-tolerated sedation [15]. Current guidelines support the use of propofol-based sedation as compared with traditional sedation with benzodiazepines and/or opioids, thus offering higher patient and endoscopist satisfaction and decreasing procedure duration as well as recovery time, without increasing the rate of adverse events [16,17]. Propofol-based sedation shows no significant difference regarding complication rate in comparison with traditional sedative agents [18]. In this study, we showed that the two most common methods of propofol administration continuous infusion and intermittent bolus resulted in nearly identical propofol dosage during ERCP, even when adjusted for body weight.

While ERCP was used in the beginning of endoscopy as a diagnostic tool, the focus has changed to an interventional procedure with the improvement of non-invasive methods such as endoscopic ultrasonography and magnetic resonance cholangiopancreatography [19]. As the complexity of the procedure increased, requirement towards endoscopist skills has grown; adequate sedation became important for successful intervention; and procedure duration has increased. In this study, we found that total propofol dose was significantly correlated with the duration of the procedure $(r=0.695 ; \mathrm{p}<0.001)$.

Deep sedation has been achieved with a combination of propofol and midazolam. Propofol has been applied as a continuous infusion or an intermittent bolus. There was no significant difference in the characteristics and the number of interventions per patient between the

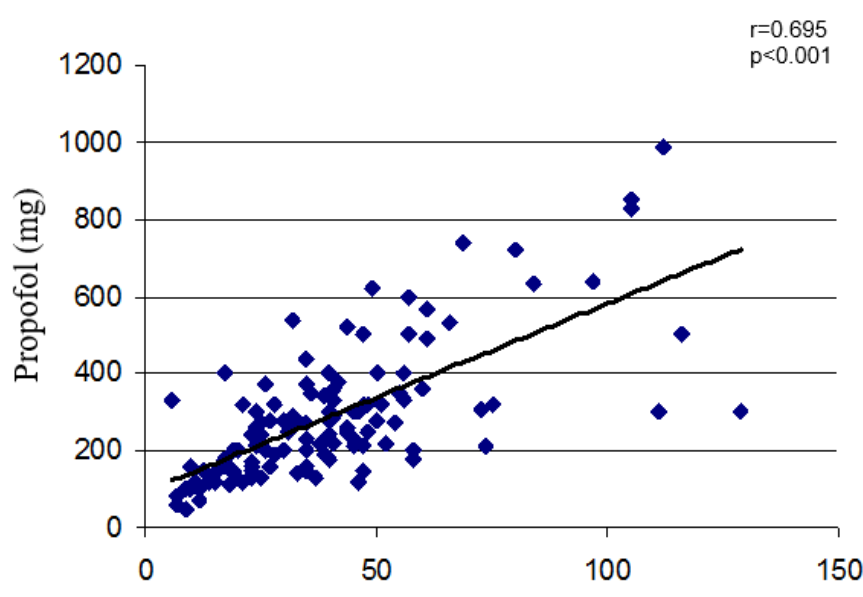

Procedure duration (min)

Figure 1. Correlation between procedure duration and propofol dosage. two groups. In general, a mean of 1.49 interventions were performed. However, the total propofol dose and procedure duration did differ significantly between the two groups. To eliminate time as a factor that might influence total propofol dose, we compared propofol dosage per minute of procedure in both groups. There was no difference between the two groups, even when propofol dosage was adjusted for body weight.

Our results are in line with the results by González-Santiago et al. [20] and Riphaus et al. [21]. The aim of those studies was to investigate safety, quality of sedation, and recovery time from propofol sedation. González-Santiago et al. [20] compared intermittent bolus with pump continuous infusion for endoscopist-directed propofol administration in colonoscopy. The pump continuous infusion group required a significantly higher total propofol dose compared to the bolus group ( $185 \mathrm{mg} v \mathrm{~s} .157 \mathrm{mg} ; \mathrm{p}=0.003$ ). The median duration of the procedure was $19 \mathrm{~min}$ in the bolus group and $21 \mathrm{~min}$ in the pump continuous infusion group. This was also observed in our study. However, in comparison to our study, González-Santiago et al. did not study the propofol dose per minute of procedure or per kg of body weight. Moreover, sedation has been performed only with propofol and not in combination with midazolam, as in our study. However, moderate sedation is considered adequate for colonoscopy. Our patients underwent ERCP, which requires deep sedation. Therefore, these results might not be entirely comparable to those obtained in our study.

In a prospective study, Riphaus et al. [21] studied intermittent manually controlled vs. continuous infusion of propofol for deep sedation during interventional endoscopy. Similar to our study, all patients received a combination of midazolam and propofol. Sixty patients underwent ERCP and 40 patients underwent endoscopic ultrasonography. The total propofol dose in the bolus group (305 \pm 155 $\mathrm{mg}$ ) was comparable with that in the perfusor group (343 $\pm 123 \mathrm{mg}$ ). There was no significant difference in the procedure duration between the two groups ( $31.4 \pm 11.3 \mathrm{~min}$ in the bolus group vs. $30.7 \pm 12.1 \mathrm{~min}$ in the perfusor group). Propofol dose per examination minute and $\mathrm{kg}$ of body weight was not investigated.

Our study has several limitations. First, this study is a retrospective study and was conducted in a single institution. A multicenter study could provide more insight with regard to examination duration and to drug dosage. Secondly, due to the retrospective nature of the study, we are not able to analyze the adverse events. This may be interesting in view of the different sedation regimens. On the other hand, the satisfaction of the patients, nurses, and endoscopists with the sedation has not been studied for the different sedation regimens. Riphaus et al. [21] showed comparable satisfaction rates for patients, nurses, and endoscopists in both groups. A possible intention to achieve a more sustained sedative effect by maintaining a preset concentration of propofol in the blood or brain, providing a higher patient satisfaction with the procedural sedation was not approved.

\section{Conclusion}

The application of propofol as a continuous infusion or an intermittent bolus resulted in nearly identical propofol dosage. There was no propofol dose reduction when propofol was administered continuously as an infusion. While published works analyzed propofol use per examination minute, we studied the weight-adjusted drug use. Both application methods can be used. However, most experience has been gained from bolus administration.

\section{Acknowledgments}

We would like to thank all endoscopy technicians who assisted the ERCPs 


\section{Funding}

This research did not receive any specific grant from funding agencies in the public, commercial, or not-for-profit sectors.

\section{References}

1. Garewal D, Powell S, Milan SJ, Nordmeyer J, Waikar P (2012) Sedative techniques for endoscopic retrograde cholangiopancreatography. Cochrane Database Syst Rev 6: CD007274. [Crossref]

2. Garewal D, Vele L, Waikar P (2013) Anaesthetic considerations for endoscopic retrograde cholangio-pancreatography procedures. Curr Opin Anaesthesiol 26: 475480. [Crossref]

3. Fanti L, Agostoni M, Gemma M, Radaelli F, Conigliaro R, et al. (2011) Sedation and monitoring for gastrointestinal endoscopy: A nationwide web survey in Italy. Dig Liver Dis 43: 726-730. [Crossref]

4. Kapoor H (2011) Anaesthesia for endoscopic retrograde cholangiopancreatography. Acta Anaesthesiol Scand 55: 918-926. [Crossref]

5. Akyuz U, Pata C, Senkal V, Erzin Y (2010) Is propofol sedation with midazolam induction safe during endoscopic procedures without anesthesiologist? Hepatogastroenterology 57: 685-687. [Crossref]

6. Ong WC, Santosh D, Lakhtakia S, Reddy DN (2007) A randomized controlled trial on use of propofol alone versus propofol with midazolam, ketamine, and pentazocine "sedato-analgesic cocktail" for sedation during ERCP. Endoscopy 39: 807-812. [Crossref]

7. Poulos JE, Kalogerinis PT, Caudle JN (2013) Propofol compared with combination propofol or midazolam/fentanyl for endoscopy in a community setting. AANA J 81: 31-36. [Crossref]

8. Ellett ML (2010) A literature review of the safety and efficacy of using propofol for sedation in endoscopy. Gastroenterol Nurs 33: 111-117. [Crossref]

9. Riphaus A (2010) Endoscopy: consensus on approving propofol sedation by nonanesthesiologists. Nat Rev Gastroenterol Hepatol 7: 187-188. [Crossref]

10. Paspatis GA, Manolaraki MM, Vardas E, Theodoropoulou A, Chlouverakis G (2008) Deep sedation for endoscopic retrograde cholangiopancreatography: intravenous propofol alone versus intravenous propofol with oral midazolam premedication. Endoscopy 40: 308-313. [Crossref]
11. Heuss LT, Froehlich F, Beglinger C (2005) Changing patterns of sedation and monitoring practice during endoscopy: results of a nationwide survey in Switzerland. Endoscopy 37: 161-166.

12. Cohen LB, Wecsler JS, Gaetano JN, Benson AA, Miller KM, et al. (2006) Endoscopic sedation in the United States: results from a nationwide survey. Am J Gastroenterol 101: 967-974. [Crossref]

13. Carlsson U, Grattidge P (1995) Sedation for upper gastrointestinal endoscopy: a comparative study of propofol and midazolam. Endoscopy 27: 240-243. [Crossref]

14. Rex DK, Deenadayalu VP, Eid E, Imperiale TF, Walker JA, et al. (2009) Endoscopistdirected administration of propofol: a worldwide safety experience. Gastroenterology 137: 1229-1237; quiz 1518-1229. [Crossref]

15. Sieg A, bng-Study- Group, Beck S, Scholl SG, Heil FJ, et al. (2014) Safety analysis of endoscopist-directed propofol sedation: a prospective, national multicenter study of 24441 patients in German outpatient practices. J Gastroenterol Hepatol 29: 517-523. [Crossref]

16. Riphaus A, Wehrmann T, Hausmann J, Weber B, von Delius S, et al. (2016) Update S3-guideline: "sedation for gastrointestinal endoscopy" 2014 (AWMF-register-no. 021/014). Z Gastroenterol 54: 58-95. [Crossref]

17. Dietrich CG, Kottmann T, Diedrich A, Drouven FM (2013) Sedation-associated complications in endoscopy are not reduced significantly by implementation of the German S-3-guideline and occur in a severe manner only in patients with ASA class III and higher. Scand J Gastroenterol 48: 1082-1087. [Crossref]

18. Qadeer MA, Vargo JJ, Khandwala F, Lopez R, Zuccaro G (2005) Propofol versus traditional sedative agents for gastrointestinal endoscopy: a meta-analysis. Clin Gastroenterol Hepatol 3: 1049-1056. [Crossref]

19. Rösch T (2012) Progress in endoscopy: areas of current interest and topics to watch out for. Endoscopy 44: 1148-1157. [Crossref]

20. González-Santiago JM, Martín-Noguerol E, Vinagre-Rodríguez G, Hernández-Alonso M, Dueñas-Sadornil C, et al. (2013) Intermittent boluses versus pump continuous infusion for endoscopist-directed Propofol administration in colonoscopy. Rev Esp Enferm Dig 105: 378-384. [Crossref]

21. Riphaus A, Geist C, Schrader K, Martchenko K, Wehrmann T (2012) Intermittent manually controlled versus continuous infusion of propofol for deep sedation during interventional endoscopy: a prospective randomized trial. Scand J Gastroenterol 47: 1078-1085. [Crossref]

Copyright: (C2017 Seyitoglu D. This is an open-access article distributed under the terms of the Creative Commons Attribution License, which permits unrestricted use, distribution, and reproduction in any medium, provided the original author and source are credited. 